\title{
MATURAÇÃO E DETERMINAÇÃO DO PONTO DE COLHEITA DE FRUTOS DE ENVIRA-CAJU ${ }^{1}$
}

\author{
JOSIANNY FEITOSA DE FARIAS², SEBASTIÃO ELVIRO DE ARAÚJO NETO, \\ VIRGÍNIA DE SOUZA ÁLVARES ${ }^{4}$, PEDRO ALBUQUERQUE FERRAZ ${ }^{5}$, \\ DENISE TEMPORIM FURTADO ${ }^{6}$ MARIA LUZENIRA DE SOUZA ${ }^{7}$
}

RESUMO - O presente trabalho objetivou identificar o ponto de colheita, os índices de maturação e a qualidade dos frutos da envireira-caju (Onychopetalum periquino). Os frutos foram colhidos em cinco estádios de maturação (1-verde; 2-verde-laranja; 3-laranja; 4-laranja-vinho, e 5-vinho), sendo o estádio 5 colhido já amadurecido na planta e usado como padrão na determinação do ponto de colheita e do índice de qualidade do fruto. Os frutos colhidos foram armazenados a $26 \pm 3{ }^{\circ} \mathrm{C}$ e $85-90 \%$ de UR. O delineamento experimental foi o inteiramente casualizado, em esquema de parcela subdividida no tempo com tratamento adicional, com quatro repetições de três frutos cada. As parcelas compreenderam os estádios de maturação na colheita, e as subparcelas, a maturação no dia da análise ( 0 dia para todos os estádios, 4 dias para os estádios 1 e 2, e 2 dias para os estádios 3 e 4). A interação entre o ponto de colheita e o armazenamento afetou significativamente todas as variáveis analisadas, exceto o rendimento de polpa. Os frutos colhidos no estádio verde-laranja atingiram índices de qualidade equivalente aos frutos amadurecidos na planta, após o amadurecimento. O ponto de colheita dos frutos corresponde à cor verde-laranja da casca, contendo $0,14 \%$ de acidez total titulável (AT); 8,62\% de sólidos solúveis (SS); 64,17 de SS/AT; 60,55 g de peso médio, e 60,37\% de rendimento de polpa, constituindo índices confiáveis do ponto de colheita.

Termos para indexação: Onychopetalum periquino, frutas nativas, pós-colheita, qualidade.

\section{MATURATION AND DETERMINATION OF THE HARVEST POINT OF ENVIRA-CAJU FRUIT}

\begin{abstract}
The present work has the objective to identify the harvest point, maturity and quality indexes of the fruits of the envireira-caju (Onychopetalum periquino). The fruits were harvested at five maturity stage (1-green, 2-green-orange, 3-orange, 4-orange-wine, 5-color wine), being the stage 5 ripened in the plant and used as pattern in the determination of the harvest point and of the maturity and quality indexes of the fruit. The harvested fruits were storage in condition it adapts $\left(26 \pm 3{ }^{\circ} \mathrm{C}\right.$ and $85-90 \%$ relative humidity). The experimental design was completely randomized in split-plot arrangement, with additional treatment, with four repetitions, containing each replication three fruits. The plot corresponded to the maturity storage and the split-plot by the ripened stage (zero day for to all stages and four day for estages 1 and 2 and of 2 days to the stages 3 and 4). The interaction among the maturation stage in the harvest and in the storage it affected significantly all the analyzed variables, except the pulp revenue. The fruits harvested in the stage green-orange they present larger shelf life and equivalent quality indexes to the fruits ripened in the plant, after the ripening. The harvest point of the envira-caju fruits can be harvested when it reaches $0.14 \%$ of titratable total acidity (TTA), 8.62\% of soluble solids (SS), 64.17 of SS/TTA, $60.55 \mathrm{~g}$ of medium weight and $60.37 \%$ of pulp revenue, constituting reliable indexes of the harvested point.
\end{abstract}

Index terms: Onychopetalum periquino, native fruits, postharvest,quality.

\footnotetext{
1(Trabalho 191-10). Recebido em:16-08-2010. Aceito para publicação em: 15-02-2011.

${ }^{2} \mathrm{Eng}^{\mathrm{a}}$. Agra'. M.Sc. Produção vegetal. Universidade Federal do Acre. Rio Branco, Acre. E-mail:j.f.farias@yahoo.com.br

${ }^{3} \mathrm{Eng}^{\circ}$. Agr ${ }^{\circ}$. Dr. Fitotecnia. Universidade Federal do Acre. Rio Branco, Acre. E-mail:selviro2000@yahoo.com.br

${ }^{4}$ Eng $^{\mathrm{a}}$. Agr ${ }^{\mathrm{a}}$. Dra. Fitotecnia: Embrapa Acre. Rio Branco, Acre. E-mail: virginia@cpafac.embrapa.br

${ }^{5}$ Biólogo. M.Sc. Produção vegetal. Universidade Federal do Acre. Rio Branco, Acre. E-mail paferraz@ufac.br

${ }^{6} \mathrm{Eng}^{\mathrm{a}}$. Agr ${ }^{\mathrm{a}}$. M.Sc. Produção vegetal. UFAC. Rio Branco, Acre. E-mail:denisetemporim@hotmail.com

${ }^{7} \mathrm{Eng}^{\mathrm{a}}$. Agr ${ }^{\mathrm{a}}$. Dra. Ciências do Alimento. UFAC. Rio Branco, Acre.E-mail: mluzen@hotmail.com
} 


\section{INTRODUÇÃO}

O Brasil possui grande potencial de produção de frutas, como banana, mamão, manga, abacaxi, uva, melão, maçã, dentre outras, que são consumidas no mercado interno e externo. Porém, outras frutas regionais "raras" (exóticas e nativas) também possuem alto potencial de mercado, incluindo acerola, atemoia, bacuri, castanhas, cajá, seriguela, mangaba, sapoti, graviola, araticum e outras, que necessitam ser estudadas (ALVES et al., 2008; BRAGA-FILHO et al., 2009).

O envira-caju (Onychopetalum periquino) pertence à família Annonaceae, é distribuído na Amazônia brasileira (Acre, Amazonas, Mato Grosso, Rondônia), peruana (Madre de Dios) e boliviana (Beni, Santa Cruz) (MAAS et al., 2007). A árvore mede de 8 a $30 \mathrm{~m}$ de altura e 15 a $40 \mathrm{~cm}$ de diâmetro. Suas folhas têm pecíolo de 4 a $7 \mathrm{~mm}$ de comprimento e de 1,5 a 2,5 mm de diâmetro, base aguda, raramente obtusa, ápice acuminado ( 5 a $20 \mathrm{~mm}$ de comprimento) e nervuras secundárias confusas. As inflorescências localizam-se em ramos mais velhos, raramente entre folhas, e os entrenós são axiais de $2 \mathrm{~mm}$ de comprimento. A floração e a antese da envireira-caju ocorrem nos meses de agosto a outubro, período de mais baixa precipitação e umidade relativa do ar na região. A frutificação ocorre de agosto a março, com presença concomitante de frutos maduros e imaturos. O fruto é uma baga de polpa amarelada e doce, com sabor e aroma agradáveis, que ao longo de seu desenvolvimento passa do verde-escuro para o amarelo até atingir, quando maduro, a cor vinho (MAAS et al. 2007).

O ponto de colheita e o manejo pós-colheita dos frutos dependem do padrão fisiológico de cada fruto. As anonáceas, como graviola (Annona muricata), cherimoia (A. cherimola) e ata (A. squamosa), são denominadas climatéricas e apresentam padrão de liberação de $\mathrm{CO}_{2}$ bastante distinto da maioria das espécies, com climatério difuso, com mais de um ponto máximo. Juntamente com o climatério respiratório, ocorre a produção autocatalítica de etileno, e os frutos continuam o processo de amadurecimento após a colheita (ALVES et al., 1997; LIMA et al., 2003). Assim, geralmente os frutos climatéricos, como as anonáceas, podem ser colhidos em estádios iniciais de maturação, com possibilidade de amadurecimento e boa qualidade pós-colheita (ALVES et al., 1997; CHITARRA; CHITARRA, 2005).

$\mathrm{O}$ amadurecimento nas anonáceas, como cherimoia e graviola, vem acompanhado de aumento nos teores de sólidos solúveis e acidez, perda de água, redução da firmeza, a cor da polpa perde o brilho e fica mais clara (LIMA et al., 2003; GOÑI et al., 2007). Estes fenômenos estão associados ao aumento do pico respiratório e de etileno (LIMA et al., 2003), hidrólise do amido e modificações da parece celular (GOÑI et al., 2010).

Apesar do pouco conhecimento científico sobre indicadores de colheita e maturação de frutos da envireira-caju, estes possuem uma característica favorável na tomada de decisão do ponto ideal de colheita pela sua mudança na coloração da casca, evoluindo de verde, quando imaturo, passando para verde-laranja, laranja, laranja-vinho e vinho, quando totalmente maduro. Uma vantagem em relação a outras Anonáceas, como a graviola, atemoia (A. cherimola $\mathrm{x}$ A. squamosa), cherimoia e ata, que promovem poucas mudanças visuais durante a maturação (WORRELL et al., 1994; ALVES et al., 1997). Para a realização deste trabalho, não foi encontrada literatura disponível sobre colheita, manuseio, amadurecimento e conservação pós-colheita do Envira-caju.

O objetivo deste trabalho foi identificar o ponto de colheita, os índices de maturação a e qualidade dos frutos da envireira-caju.

\section{MATERIAL E MÉTODOS}

Os frutos da envireira-caju utilizados foram coletados de árvores selecionadas na área da Reserva Florestal do Câmpus da Universidade Federal do Acre - UFAC, em Rio Branco, Acre, representada por formações vegetais secundárias, em diferentes estágios de regeneração.

Os frutos foram colhidos de cinco árvores com aproximadamente 25 anos e com 18 anos de vida produtiva, escolhidas pelas características vegetativas e produtivas homogêneas.

Os frutos foram colhidos em fevereiro de 2008, nas primeiras horas da manhã, para evitar as perdas por transpiração e transportados em sacos plásticos para o Laboratório da Unidade de Tecnologia de Alimentos na UFAC. Estes foram colhidos em 5 estádios de maturação, segundo a coloração da casca, determinada visualmente pela cor predominante: Estádio 1: verde; Estádio 2: verde-laranja; Estádio 3: laranja; Estádio 4: laranja-vinho; Estádio 5: vinho (Figura 1).

Por terem sido colhidos na planta a 8 metros de altura, os frutos apresentavam-se aparentemente limpos, por isso, como manuseio pós-colheita, utilizou-se apenas a lavagem com água corrente para a remoção das sujidades. Após a lavagem, os frutos foram secos ao ar e divididos em dois grupos.

No primeiro grupo, as análises foram rea- 
lizadas no dia da colheita para os cinco estádios de maturação, e o segundo grupo, composto de quatro estádios de maturação $(1 ; 2 ; 3$ e 4$)$, foi armazenado em sala com temperatura ambiente de aproximadamente $26 \pm 3{ }^{\circ} \mathrm{C}$ e umidade relativa do ar de $85-90 \%$ e analisado ao atingir o completo amadurecimento. Assim, os frutos dos estádios 3 e 4 atingiram o amadurecimento no $2^{\circ}$ dia após a colheita, e os frutos dos estádios 1 e 2 atingiram o amadurecimento no $4^{\circ}$ dia após a colheita. $\mathrm{O}$ estádio 5 não foi armazenado por se encontrar amadurecido na planta, sendo analisado no dia da colheita, com objetivo de utilizá-lo como padrão na determinação do ponto de colheita, índice de qualidade e caracterização.

As características analisadas foram: comprimento $(\mathrm{mm})$, diâmetro $(\mathrm{mm})$, índice de formato, número de sementes, sólidos solúveis $(\%)$, acidez total titulável (\%), relação SS/AT, massa fresca do fruto $(\mathrm{g})$ e rendimento de polpa $(\%)$.

O comprimento e o diâmetro dos frutos foram medidos utilizando paquímetro digital com $0,01 \mathrm{~mm}$ de precisão. $\mathrm{O}$ índice de formato serve para determinar a forma do fruto (cilíndrica, cônica ou ovoide), e foi determinado pela relação diâmetro longitudinal e transversal (DL/DT). O teor de sólidos solúveis foi determinado por meio da leitura direta em refratômetro digital, com controle automático de temperatura e leitura na faixa de 0 a 32\% (BRASIL, 2005). A acidez total titulável, determinada pela titulação da amostra com hidróxido de sódio $(\mathrm{NaOH}, 0,1 \mathrm{~N})$, foi expressa em porcentagem de ácido cítrico (AOAC, 1990). A relação sólidos solúveis/acidez total titulável constitui o quociente entre a razão SS/AT. A massa fresca do fruto foi determinada em balança analítica de precisão, expressa em gramas (g). O rendimento de polpa dos frutos em porcentagem foi determinado pelo quociente da razão entre a massa fresca do fruto com casca e semente pela polpa, multiplicado por 100 .

Foram considerados como indicadores de qualidade as características físicas, físico-químicas e químicas dos frutos amadurecidos na planta. E os indicadores de maturação, as características físicas e de composição do fruto no ponto definido como ideal para colheita, identificados como maturação fisiológica. O ponto de colheita (maturação fisiológica) foi considerado aquele no qual o fruto nos diferentes estádios de maturação atingiu qualidade equivalente aos frutos amadurecidos na planta.

O delineamento experimental utilizado foi o inteiramente casualizado, em esquema de parcela subdividida no tempo, com tratamento adicional, com quatro repetições, contendo cada repetição três frutos. As parcelas compreenderam os estádios de maturação na colheita, e as subparcelas, a maturação no dia da análise (armazenamento). O tratamento adicional correspondeu aos frutos amadurecidos na planta. Os frutos do fatorial (estádios de maturação e armazenamento) foram comparados entre si, pelo teste de Tukey, a 5\% de probabilidade do erro, e a comparação destes com os frutos amadurecidos na planta, através do teste de Dunnet, a $5 \%$ de probabilidade do erro.

\section{RESULTADOS E DISCUSSÃO}

Houve diferença significativa de todas as variáveis analisadas para a interação entre os fatores estádio de maturação e armazenamento, e para a interação do fatorial com o tratamento adicional, exceto a variável acidez total titulável, que não diferiu do padrão, e a variável rendimento de polpa que apresentou diferença significativa apenas para o fator maturação dos frutos na planta e entre o tratamento-padrão.

$\mathrm{O}$ fruto de envireira-caju amadurecido na planta mede aproximadamente $42,8 \pm 8,5 \mathrm{~mm}$ de comprimento, 48,8 $\pm 10,0 \mathrm{~mm}$ de diâmetro e 1,2 \pm 0,1 índice de formato, portanto de forma globosa, e possui em média $4,7 \pm 1,8$ sementes por fruto (Tabela 1).

Possuem características próprias para consumo in natura, com 11,7 $\pm 0,8$ de sólidos solúveis, baixa acidez $(0,16 \pm 0,1 \%)$ e relação $\mathrm{SS} / \mathrm{AT}$ de $76,6 \pm 20,5$ (Tabela 1), caracterizando uma fruta de sabor agradável e muito apreciada por animais silvestres e populações tradicionais. No entanto, os frutos apresentam sabor adstringente em estádio de amadurecimento incompleto.

No dia da colheita, não houve diferença na acidez total titulável, entre os estádios de maturação; porém, em frutos dos estádios verde-laranja e laranja, ocorreu aumento significativo da acidez durante o amadurecimento (Tabela 2).

Esse comportamento é comum nas Anonáceas, como em graviola, que coincide com o aumento respiratório e primeiro pico de $\mathrm{CO}_{2}$ (LIMA et al., 2003), indicando que pode ser consequência da ativação da glicólise induzida pela colheita, com intensa oxidação de glicose e hidrólise de amido (BRUINSMA; PAULL, 1984). Em graviola, o amadurecimento do fruto foi estimulado com a liberação de etileno aos três dias após a colheita, por ocasião do primeiro pico respiratório (LIMA et al., 2003).

Após o amadurecimento dos frutos, não houve diferença significativa entre os estádios de maturação para o teor de sólidos solúveis (Tabela 2). No entanto, apenas os estádios laranja e laranja-vinho 
apresentaram o mesmo teor de sólidos solúveis dos frutos amadurecidos na planta (estádio vinho), inclusive no dia da colheita. Este comportamento é decorrente do maior teor de carboidratos (amido, sacarose, frutose, glicose e outros) em frutos, no momento da colheita, que após a hidrólise do amido e da quebra parcial de pectina, celulose e outros polissacarídeos, os frutos atingem teores de sólidos solúveis semelhantes aos frutos em estádio avançado de maturação (LIMA et al., 2003; LIMA et al., 2006).

Os frutos colhidos verde e verde-laranja aumentaram os teores de sólidos solúveis para 12,87 e $10,38{ }^{\circ}$ Brix, respectivamente, após o amadurecimento (Tabela 2). Em graviola, o primeiro pico respiratório e o pico de etileno podem ter um envolvimento mais direto no ganho de sólidos solúveis (LIMA et al., 2003), por estimular o metabolismo do fruto com intensa redução do conteúdo de amido, redução de pectina total e aumento na solubilização de pectinas, fenômenos relacionados com intensa atividade das enzimas amilase, pectinametilesterase, poligalacturonase e betagalactosidase de parede celular (LIMA et al., 2006).

Frutos verdes ainda não apresentam maturação bioquímica e fisiológica para completar o amadurecimento e transformar açúcar em ácidos, e amido em açúcar, por isso os valores baixos de sólidos solúveis (CHITARRA; CHITARRA, 2005). Em graviola, o maior acúmulo de SS ocorre antes do aumento para o pico climatérico, por isso acreditase que a ocorrência do primeiro pico respiratório e do pico de etileno pode ter um envolvimento mais direto no ganho de SS, possivelmente por estimular reações que produzem precursores para compostos daquela natureza (LIMA et al., 2003).

Tanto no dia da colheita quanto após o amadurecimento, a relação SS/AT aumentou com o estádio de maturação. No estádio laranja-vinho, o processo de amadurecimento já está avançado, por isso não houve aumento significativo dessa relação após o armazenamento.

Nos estádios verde-laranja e laranja, ocorreu diminuição da relação SS/AT após o amadurecimento do fruto (Tabela 2), em consequência do aumento significativo da acidez nestes dois estádios (Tabela 2). Este comportamento de aumento da acidez em frutos durante o amadurecimento é comum em frutos das espécies da família das anonáceas (BRUINSMA; PAULL, 1984).

Considerando a relação SS/AT como índice de qualidade, os estádios verde-laranja, laranja e laranja-vinho apresentaram o mesmo padrão de qualidade que os frutos amadurecidos na planta.

No dia da colheita, houve diferença significativa na massa fresca dos frutos entre os estádios de maturação, com frutos maiores no estádio laranja-vinho, mas após o amadurecimento, essa diferença desapareceu, indicando que pode ter ocorrido alta perda de massa (Tabela 3 ).

Após o amadurecimento dos frutos em condição ambiente, a massa variou de 21,29 a $34,04 \mathrm{~g}$, muito abaixo da massa fresca dos frutos amadurecidos na planta, de $86,94 \mathrm{~g}$. Isto revela que o armazenamento do envira-caju, nestas condições, promove alta perda de massa, apesar de apresentarem aparência externa em qualidades para o consumo in natura; mesmo assim, tornam-se necessárias tecnologias de pós-colheita para reduzir a transpiração do fruto. Esse comportamento já foi observado em graviola, que mesmo com 5\% de perda de massa, não apresenta sinais de enrugamento e perda de qualidade comercial (LIMA et al., 2006). Em frutos de cherimoia, esta perda de massa constitui-se principalmente por perda de água, que está associada à redução da firmeza, atividade hidrolítica e expressão de quitinase ácida e básica, resultando na hidrólise do amido e modificações da parede celular (GOÑI et al., 2007; GOÑI et al., 2010).

Os frutos de envireira-caju apresentaram maior rendimento de polpa nos estádios verde-laranja, laranja e laranja-vinho, com $62 \%, 68,4 \%$ e $70 \%$ de polpa, respectivamente, e não diferiram do padrão (fruto amadurecido na planta) (Tabela 4).

Observa-se que o rendimento de polpa em frutos de envireira-caju aumenta com o avanço da maturação. O rendimento obtido dos frutos amadurecidos na planta $(70,4 \%)$ é superior aos resultados encontrados em outras Anonáceas, como a atemoia com 56,6\% de rendimento de polpa (NEVES;YUHARA, 2003). 

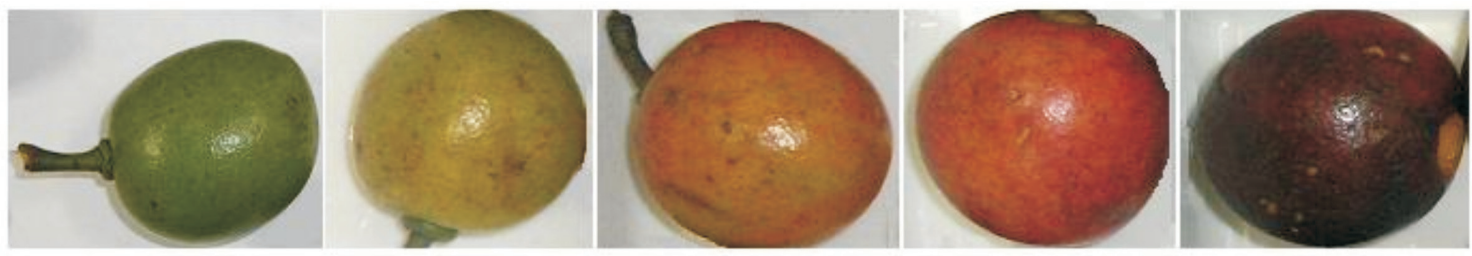

FIGURA 1 - Frutos em diferentes estádios de maturação: 1 (verde); 2 (verde-laranja); 3 (laranja); 4 (laranjavinho), e 5 (vinho), respectivamente.

TABELA 1 - Caracterização de frutos maduros de Envira-caju. (Dados de campo)

\begin{tabular}{lc}
\hline \multicolumn{1}{c}{ Variável } & Médias \pm Desvio-Padrão \\
\hline Acidez Total titulável - AT (\%) & $0,16 \pm 0,1$ \\
Sólidos Solúveis - SS (\%) & $11,7 \pm 0,8$ \\
Relação SS/AT & $76,6 \pm 20,5$ \\
Massa Fresca - MF (g) & $83,4 \pm 27,9$ \\
Rendimento de Polpa (\%) & $70,4 \pm 3,1$ \\
Diâmetro (mm) & $42,8 \pm 8,5$ \\
Comprimento (mm) & $48,8 \pm 10,0$ \\
Índice de Formato & $1,2 \pm 0,1$ \\
Peso da Semente (g) & $2,6 \pm 1,1$ \\
Número de Sementes & $4,7 \pm 1,8$ \\
Cor & Vinho \\
\hline
\end{tabular}

TABELA 2 - Acidez total titulável (AT) e sólidos solúveis (SS) dos frutos de envira-caju colhidos em quatro estádios de maturação e amadurecidos fora da planta, em temperatura ambiente. Rio Branco, Acre, UFAC, 2008. ${ }^{1}$

\begin{tabular}{|c|c|c|c|c|}
\hline \multirow{3}{*}{$\begin{array}{c}\text { Estádio de maturação } \\
\text { (Cor da casca) }\end{array}$} & \multicolumn{4}{|c|}{ Período de armazenamento ${ }^{2}$} \\
\hline & \multicolumn{2}{|c|}{$\begin{array}{c}\text { Acidez Total } \\
\text { (ácido cítrico - \%) }\end{array}$} & \multicolumn{2}{|c|}{$\begin{array}{c}\text { Sólidos Solúveis } \\
(\%)\end{array}$} \\
\hline & $\mathrm{Na}$ Colheita & Maduro & $\mathrm{Na}$ Colheita & Maduro \\
\hline Verde & $0,23 \mathrm{aA}^{\mathrm{ns}}$ & $0,20 \mathrm{bA}^{\mathrm{ns}}$ & $4,00 \mathrm{cB}^{*}$ & $12,87 \mathrm{aA}^{*}$ \\
\hline Verde-Laranja & $0,14 \mathrm{aB}^{\mathrm{ns}}$ & $0,46 \mathrm{aA} * 3$ & $8,62 \mathrm{bA}^{*}$ & $10,38 \mathrm{aA}^{*}$ \\
\hline Laranja & $0,14 \mathrm{aB}^{\mathrm{ns}}$ & $0,34 \mathrm{abA} *$ & $12,62 \mathrm{aA}^{\mathrm{ns}}$ & $11,64 \mathrm{aA}^{\mathrm{ns}}$ \\
\hline Laranja-Vinho & $0,11 \mathrm{aA}^{\mathrm{ns}}$ & $0,14 \mathrm{bA}^{\mathrm{ns}}$ & $11,37 \mathrm{aA}^{\mathrm{ns}}$ & $10,59 \mathrm{aA}^{\mathrm{ns}}$ \\
\hline \multirow[t]{2}{*}{ Vinho - Amadurecido na plan } & 0,16 & & & 11,63 \\
\hline & \multicolumn{2}{|c|}{ CV $20,28 \%$} & \multicolumn{2}{|c|}{ CV 11,39} \\
\hline
\end{tabular}

1. Em cada coluna, médias seguidas pela mesma letra minúscula e, em cada linha, pela mesma letra maiúscula não diferem significativamente entre si, pelo teste de Tukey $(\mathrm{P}<0,05)$.

2. Armazenamento de 4 dias para os estádios verde e verde-laranja e 2 dias para os estádios laranja e laranja-vinho.

3. Médias que diferem (*) e que não diferem (ns) significativamente com a média do tratamento adicional (fruto amadurecido na planta), pelo teste Dunnet, a 5\% de probabilidade. 
TABELA 3 - Massa fresca do fruto e relação SS/AT de frutos de envira-caju colhidos em quatro estádios de maturação e amadurecidos fora da planta, em temperatura ambiente. Rio Branco, Acre, UFAC, $2008^{1}$.

\begin{tabular}{|c|c|c|c|c|}
\hline \multirow{3}{*}{$\begin{array}{c}\text { Estádio de maturação } \\
\text { (Cor da casca) }\end{array}$} & \multicolumn{4}{|c|}{ Período de armazenamento ${ }^{2}$} \\
\hline & \multicolumn{2}{|c|}{$\begin{array}{c}\text { Massa Fresca } \\
\left(\mathrm{g} \text { fruto }^{-1}\right)\end{array}$} & \multicolumn{2}{|c|}{ Relação SS/AT } \\
\hline & $\mathrm{Na}$ Colheita & Maduro & $\mathrm{Na}$ Colheita & Maduro \\
\hline Verde & $54,47 \mathrm{bA}{ }^{\mathrm{ns}}$ & $21,29 \mathrm{aB}^{*}$ & $17,04 \mathrm{cB}^{*}$ & $65,08 \mathrm{aA}^{*}$ \\
\hline Verde-Laranja & $60,55 \mathrm{bA}^{\mathrm{ns}}$ & $27,72 \mathrm{aB}^{*}$ & $64,17 \mathrm{bA} \mathrm{ns}^{\mathrm{ns}}$ & $24,15 \mathrm{cB}^{\mathrm{ns}}$ \\
\hline Laranja & $50,91 \mathrm{bA} *$ & $33,57 \mathrm{aA}^{*}$ & $89,99 \mathrm{abA}^{\mathrm{ns}}$ & $54,22 \mathrm{abB}$ ns \\
\hline Laranja-Vinho & $126,07 \mathrm{aA}^{\mathrm{ns}}$ & $34,04 \mathrm{aB}^{*}$ & $104,75 \mathrm{aA}^{\mathrm{ns}}$ & $77,44 \mathrm{aA}^{\mathrm{ns}}$ \\
\hline \multirow[t]{2}{*}{ Vinho - Amadurecido na planta } & 86,94 & & & 76,30 \\
\hline & \multicolumn{2}{|c|}{ CV $20,28 \%$} & \multicolumn{2}{|c|}{ CV 9,19\% } \\
\hline
\end{tabular}

1. Em cada coluna, médias seguidas pela mesma letra minúscula e, em cada linha, pela mesma letra maiúscula não diferem significativamente entre si, pelo teste de Tukey $(\mathrm{P}<0,05)$.

2. Armazenamento de 4 dias para os estádios verde e verde-laranja e 2 dias para os estádios laranja e laranja-vinho.

3. Médias que diferem $(*)$ e que não diferem (ns) significativamente com a média do tratamento adicional (fruto amadurecido na planta), pelo teste Dunnet, a 5\% de probabilidade.

TABELA 4 - Rendimento de polpa (\%) dos frutos de envireira-caju colhidos em quatro estádios de maturação e amadurecidos fora da planta, em temperatura ambiente. Rio Branco, Acre, UFAC, 2008.

\begin{tabular}{cccc}
\hline \multirow{2}{*}{$\begin{array}{c}\text { Estádio de maturação } \\
\text { (Cor da casca) }\end{array}$} & \multicolumn{3}{c}{ Período de armazenamento ${ }^{2}$} \\
Dia da Colheita & Maduro & Média \\
\hline Verde & 51,91 & 50,00 & $51,0 \mathrm{~b}^{* 3}$ \\
Verde-Laranja & 60,37 & 63,33 & $62,0 \mathrm{ab}^{\mathrm{ns}}$ \\
Laranja & 68,42 & 68,34 & $68,4 \mathrm{a}^{\mathrm{ns}}$ \\
Laranja-Vinho & 72,00 & 67,91 & $70,0 \mathrm{a}^{\mathrm{ns}}$ \\
\hline Vinho - Fruto amadurecido na planta & 70,4 & & \\
\hline CV 11,33\% & & \\
\hline
\end{tabular}

1. Em cada coluna, médias seguidas pela mesma letra minúscula não diferem significativamente entre si, pelo teste de Tukey $(\mathrm{P}<0,05)$.

2. Armazenamento de 4 dias para os estádios verde e verde-laranja e 2 dias para os estádios laranja e laranja-vinho.

3. Médias que diferem $\left(^{*}\right)$ e que não diferem (ns) significativamente com a média do tratamento adicional (fruto amadurecido na planta), pelo teste Dunnet, a $5 \%$ de probabilidade.

\section{CONCLUSÃO}

1- Frutos de envira-caju colhido no início da maturação, com a casca verde-laranja apresentam, qualidade semelhante aos frutos amadurecidos na planta e os seguintes índices de colheita: $0,14 \%$ de acidez total titulável, $8,62 \%$ de sólidos solúveis, 64,17 de relação SS/AT, $60,55 \mathrm{~g}$ de peso médio e $60,37 \%$ de rendimento de polpa.

2-Os índices de qualidade do envira-caju constituem-se de $11,7 \% \pm 0,8 \%$ de sólidos solúveis, $0,16 \% \pm 0,1 \%$ de acidez total titulável, relação SS/ AT de 76,6 $\pm 20,5$ e cor vinho da casca.

\section{AGRADECIMENTOS}

À Coordenadoria de Aperfeiçoamento de pessoal de Nível Superior (CAPES), pela concessão de bolsa à primeira autora.

\section{REFERÊNCIAS}

ALVES, R. E.; FILGUEIRAS, H. A. C.; MOSCA, J. L. Colheita e pós-colheita de Anonáceas. In: SÃO JOSÉ, A.R.; SOUZA, I.V.B.; MORAIS, O.M. et al. Anonáceas: produção e mercado (pinha, graviola, atemoia e cherimólia).Vitória da Conquista: DFZ/ UESB, 1997. p. 240-256. 
AOAC. ASSOCIATION OF OFFICIAL ANALITICAL CHEMISTS. Official methods of analysis of the Association of Official Analitical Chemists. $15^{\text {th }}$ ed. Washington, 1990. $2 \mathrm{v}$.

BRAGA FILHO, J. R.; NAVES, R. V.; VELOSO, V. da R. S.; CHAVES, L. J.; NASCIMENTO, J. N. do; AGUIAR, A. V. Produção de frutos e caracterização de ambientes de ocorrência de plantas nativas de araticum no cerrado de Goiás. Revista Brasileira de Fruticultura, Brasília, v.31, n.2, p. 461-473, 2009.

BRASIL. Ministério da Saúde. Agência Nacional de Vigilância Sanitária. Métodos físicos-químicos para análise de alimentos. Brasília, 2005.

BRUINSMA, J.; PAULL, R. E. Respitation during postharvest development of soursop fruit, Annona muricata L. Plant Physiology, Rockville, v. 76, n. 1, p. 131-138, 1984.

CHITARRA, M. I. F.; CHITARRA, A. B. Póscolheita de frutos e hortaliças: fisiologia e manuseio. 2. ed. Lavras: UFLA, 2005. 785 p.

GOÑI, O.; MUÑOZ, M.; RUIZ-CABELLO, J.; ESCRIBANO, M. I.; MERODIO, C. Changes in water status of cherimoya fruit during ripening. Postharvest Biology and Tecnology, Amsterdam, v.45, p.147-150, 2007.

GOÑI, O.; SNACHEZ-BALLESTA, M. T.; MERODIO, C.; ESCRIBANO, M. I. Ripening-related defense proteins in Annona fruit. Postharvest Biology and Tecnology, Amsterdam, v.55, p.169-173, 2010.
LIMA, M. A. C. de; ALVES, R. E.; FILGUEIRAS, H. A. C. Mudanças relacionadas ao amaciamento da graviola durante a maturação pós-colheita. Pesquisa Agropecuária Brasileira, Brasília, v.41, n.12, p.1707-1713, 2006.

LIMA, M. A. C. de; ALVES, R. E.; FILGUEIRAS, H. A. C.; ENÉAS-FILHO, J. Comportamento respiratório e qualidade pós-colheita de graviola (Annona muricata L.) 'morada' sob temperatura ambiente. Revista Brasileira de Fruticultura, Jaboticabal, v. 25, n. 1, p.49-52, 2003.

MAAS, P. J. M.; WESTRA, L. Y. TH.; M. VERMEER. Revision of the neotropical genera Bocageopsis, Onychopetalum, and Unonopsis (Annonaceae). Nationaal Herbarium Nederland, Leiden University branch. BLUMEA, Leiden, v.52, p. 413-554, 2007.

NEVES, C. S. V. J.; YUHARA, E. N. Caracterização dos frutos de cultivares de atemoia produzidos no norte do Paraná. Semina: Ciências Agrárias, Londrina, v. 24, n. 2, p. 311-314, 2003.

WORRELL, D.B.; CARRINGTON, C.M.S.; HUBER, D.J. Growth, maturation and ripening of soursop. Scientia Horticulturae, Amsterdam, v.57, n.1, p.7-15, 1994 